\title{
NILAI PENDIDIKAN KARAKTER PADA FILM "HICKHI" (CEGUKKAN) DAN IMPLEMENTASINYA TERHADAP PEMBELAJARAN BAHASA INDONESIA
}

\author{
Rifani Sayira Wijaya, Lisa Septia Dwi Br. Ginting \\ 1. Universitas Muslim Nusantara Al-Washliyah \\ 2. Universitas Muslim Nusantara Al-Washliyah
}

rifanisavirawijaya1999@gmail.com, lisaseptiadewi@umnaw.ac.id

\begin{abstract}
Abstrak. Tujuan dari penelitian ini adalah untuk menganalisis pendidikan karakter dalam film "hickhi" sebagai pembangunan karakter untuk media pembelajaran yang relevan. Sumber data diperoleh dengan mengamati cerita dari film "hickhi" secara langsung. Teknik untuk mengumpulkan data menggunakan ulasan film atau mendengarkan dan mempelajari . Hasil penelitian menunjukkan bahwa ada nilai-nilai pendidikan karakter yang disampaikan melalui adegan dalam film "hickhi". Nilai-nilai pendidikan karakter dalam film "hickhi" dapat dipahami dari dialog dan adegan yang dimainkan oleh para pemain atau aktor dalam film tersebut. Film "hickhi" berisi nilai-nilai pendidikan karakter yang relevan sebagai pembangunan karakter. Film ini dapat digunakan sebagai media pembelajaran yang bertujuan pembentukan karakter siswa.
\end{abstract}

Kata kunci: Pendidikan, karakter, Implementasi.

\begin{abstract}
The purpose of this study was to analyze character education in the film "Hickhi" as a character development for relevant learning media. The data source was obtained by observing stories from the film "Hickhi" directly. Techniques for collecting data using movie reviews or listening and learning. The results showed that there were values of character education submitted through the scene in the film "Hickhi". Character education values in the film "Hickhi" can be understood from dialogue and scenes played by players or actors in the film. The film "Hickhi" contains character education values relevant as character development. This film can be used as a learning medium aimed at the formation of student characters. Keywords: Education, Character, Implementation.
\end{abstract}

\section{PENDAHULUAN}

Dalam film "Hichki" seorang guru juga bisa mengambil pembelajaran seperti cara mengajar yang baik dimana kita ketahui siswa di zaman sekarang sangat sulit untuk di ajak serius dalam pembelajaran, sangat sedikit siswa yang serius dalam pendidikan, di film "Hichki" ini guru sangat banyak pemeblajaran yang didapat. Film "Hichki" sangat berkaitan atau berpengaruh dalam dunia pendidikan, mampu memberikan nilai-nili karakter untuk siswa kedepannya, dimana jika dipertontonkan, siswa mampu mengubah gaya berfikir mereka untuk belajar, misalnya seperti tidak ada pelahjaran yang ia tidak bisa, tidak siswa yang bodoh, kunci hanya di saat kita belajar keras untuk mengapai cita-cita maka sangat banyak cara untuk mengubah diri agar lebih mudah memahami pelajaran yang ia dapat disekolah sehingga mampu meraih cita-cita agar sukses dikemudian harinya.

Film "Hickhi" memiliki kekuatan tersendiri dimana banyak sekali adegan adegan dan dialog yang mengandung nilai nilai karakter pendidikan. Maka dari latak belakang ini, sekiranya perlu dilakukan suatu peneletian lebih lagi dalm film "Hickhi". Dalam film "Hickhi" peneliti banyak belajar bahwa dalam berbagi ilmu tidak memandang fisik dan materi. Kemudian dalam film "Hickhi" saya mengerti bahwa tempat berbagi ilmu juga tidak harus di sekolah. Banyak sekali pesan yang saya dapat dari film "Hicki" yaitu 
kejujuran, kemandirian, keberanian, kerendahan hati, dan bertanggung jawab.

Dikarena dalam film "Hickhi" seorang guru yang memiliki kekurangan atau batasan mampu mengubah banyak siswa yang tidak mampu menerima mata pelajaran di sekolah dan di kucilkan di lingkungan sekolah yang pada akhirnya mampu menerima banyak mata pelajaran dengan fasilitas terbatas dan seorang guru yang diremehkan banyak orang karena kekurangan serta keterbatasan.

\section{METODE PENELITIAN}

Pada penelitian ini peneliti menggunakanan penelitian Kualitatif Deskriptif yang didalamnya terdapat pendapat menurut beberapa para ahli mengenai pengertian dari penelitian kualitatif. Menurut Sugiono, 2019 , metode penelitian kualitatif ialah metode yang berlandaskan pada filsafat postpositivisme, yang digunakan untuk meneliti pada kondisi obyek yang almiah. Instrumen penelitian ini ialah peneliti sendiri yang dijadikan kunci utamanya, teknik pengumpulan data dilakukana secra gabungan atau bersiifat kualitatif yang lebih menekankan makna.

Lokasi yang digunakan peneliti dalam penelitian ini adalah di perpustakan Universitas Muslim Nusantara, Perpusatakaan Daerah di Medan,Sumatera udara, dan dirumah peneeliti sendiri, dari bulan Januari 2021 sampai selesai. Menurut Moleong (2001:112), pencatatan sumber data melalui wawancara atau pengamatan merupakan hasil gabungan dari kegiatan melihat, mendengar, dan bertanya. Pada penelitian kualitatif, kegiatan-kegiatan ini dilakukan secara sadar, terarah dan senantiasa bertujuan memperoleh suatu informasi yang diperlukan.

Sumber data yang digunakan penulis untuk melakukan skripsi ini ialah bahan pustaka sumber data pustaka dan buku-buku yang relevan dengan pembahasan penelitian yang digunakan sebagai skripsi, internet, penelitian yang relevan atau penelitian yang sebelumnya yang berkaitan dengan nilai pendidikan karakter. Teknik pengumpulan data dalam penelitian yang digunakan peneliti adalah dengan cara mengumpulkan beberapa pengumpulan data dokumentasi, yaitu dengan cara simak dan catat.

\section{HASIL PENELITIAN}

Nilai pendidikan Karakter Bangsa memiliki 18 karakter, menurut UU Sidiknas yaitu diantaranya mencakup nilai religious, jujur, toleransi, disiplin, kerja keras, kreatif, mandiri, demokratis, rasa ingin tahu, semangat kebangsaan, cinta tanah air, menghargai prestasi, bersahabat/ komunikatif, cinta damai, gemar membaca, peduli lingkungan, peduli sosial, tanggung jawab. Namun dari 18 pendidikan karakter tersebut peneliti hanya menemui beberapa pada film "hickhi" yang kemudian dikategorikan menjadi 3 kriteria nilai karakter bangsa yang penulis temukan, yaitu yang pertama nilai pendidikan karakter dengan diri sendiri yang didalamnya mencakup nilai pendidikan karakter jujur, disiplin, kerja keras, kreatif, tanggung jawab dan rasa ingin tahu, kedua nilai pendidikan karakter dengan sesama manusia yang didalamnya mencakup nilai pendidikan karakter demokratis, bersahabt/komunikatif fan menghargai prestasi, dan yang ketiga nilai pendidikan karakter dengan kebangsaan yang didalamnya mencakup nilai pendidikan karakter toleransi.

Nilai-Nilai Pendidikan Karakter Pada Film "Hickhi"

A. Nilai Pendidikan Karakter Dengan Diri Sendiri

1. Jujur

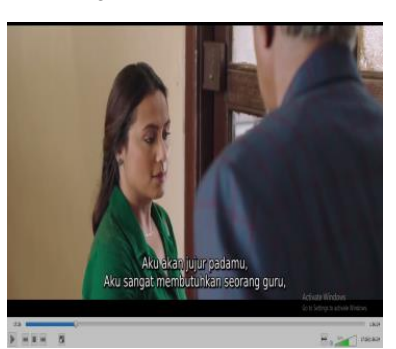

Perilaku yang didasarkan pada upaya menjadikan dirinya sebagai orang yang selalu dapat dipercaya dalam perkataan,tindakan,dan pekerjaan. Sikap jujur di tunjukkan pada menit ke 00:17:26

Kepala Sekolah : Aku akan jujur padamu, aku sangat membutuhkan seorang guru, maka dari itulah aku akan menawarimu pekerjaan guru tidak tetap ini pada mu.

\section{Disiplin}

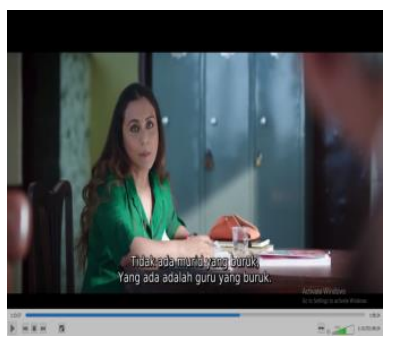

Tindakan yang menunjukkan perilaku tertib dan patuh pada berbagai

ketentuan dan peraturan. Sikap

disiplin ada pada menit ke 01:13:27

Naina : tidak ada murid yang buruk, yang telah terjadi pada siswa 9F dan mungkin akan terjadi lagi nantinya itu urusan mereka dan aku. Aku masih guru 
Rifani Sayira Wijaya Dan Lisa Septia Dwi Br. Ginting

Nilai Pendidikan Karakter pada Film "Hickhi” (Cegukkan) dan Implementasinya Terhadap Pembelajaran Bahasa Indonesia

mereka dan mereka masih muiridku (terjadi pada saat seorang guru yang menggap siswa 9F terlalu buruk dan iya berusaha membela siswa 9F kemudian menegaskan agara hanya iya yang mengetahui bagai mana bisa mengatasi siswa 9F.

3. Kerja Keras

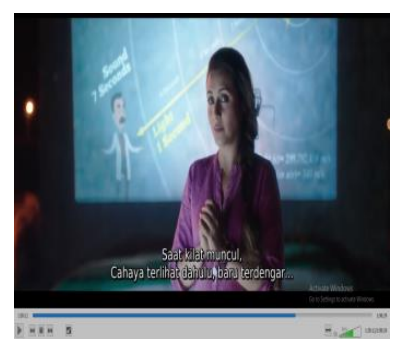

Tindakan yang menunjukkan

upaya sungguhsungguh dalam mengatasi

berbagai

hambatan belajar

dan tugas, serta menyelesaikan tugas dengab sebaik-baiknya . Sikap kerja keras pada menit ke 01:30:11

$\mathrm{Bu}$ Naina memohon agar siswa 9F tidk di scor tetapi siswa diberi kesempatan untuk tidak belajar disekolah, bu naina pun selalu melakukan berbagai cara agar siswa 9F dapat mengikuti ujian akhir meski tidak diizinkan kepala sekolah untuk dating beraktifitas disekolah sampai ujian akhir diselenggarkan sehingga naina berusaha mencari cara agar siswa 9F dapat belajar meski tidak disekolah. Misalnya di pinggir pantai, di halaman luas di lingkungan mereka, kemudian berpindah saat tak dapat ke bus di kota mereka, dan tempat lainnya di restoran milik adik naina.

4. Kreatif

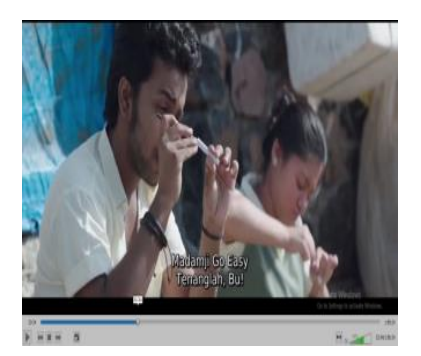

Berpikir dan melakukan

sesuatu untuk menghasilkan

cara atau hasil

baru dari sesuatu yang telah

dimiliki.

Sikap kreatif ada pada menit ke 00:33:34

Seluruh siswa kelas 9F membuat sesuatu dimana untuk naina agar ia tidak betah atau bertahan lama disekolah tersebut, dengan cara membuat balon gas, membuat kapur yang berisi abu pada korek dan lainnya.

Sikap kreatif ada pada menit ke 00:45:47

Naina membuat tempat diluar sekolah untuk dijadikan tempat belajar mengajar agar siswa tidak jenuh, kemudian menggunakan cara melempar telur rebus kepada setiap siswa untuk dijadikan umpama pada pemebelajaran matematikan dan fisika.

5. Tanggung jawab

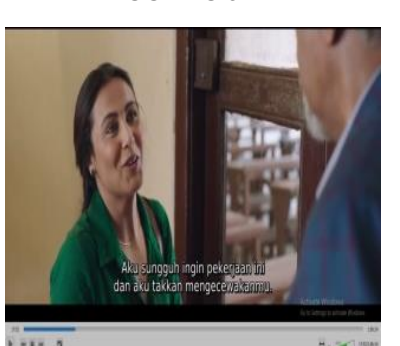

Sikap dan perilaku seseorang untuk melaksanakan tugas dan kewajibannya, yang seharusnya dia lakukan, terhadap diri sendiri, masyarakat, lingkungan, negara, dan Tuhan Yang Maha Esa . Sikap bertanggung jawab ada pada menit ke 00:17:52

Naina : aku sungguh ingin perkerjan ini, dan aku takkan menggecewakkan mu

6. Rasa Ingin Tahu

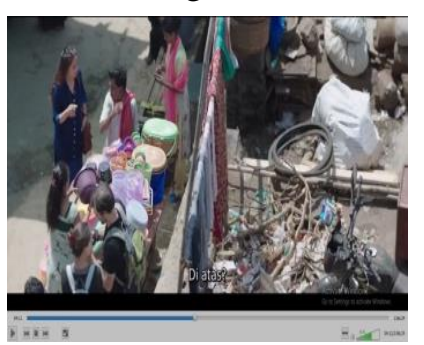

Sikap dan tindakan yang selalu berupaya untuk mengetahui lebih mendalam dalam meluas dari sesuatu yang dipelajarinya,dilihat, dan didengar. Sikap bertanggung jawab ada pada menit ke 00:54:11

Naina mencari tahu tempat tinggal siswa 9F untuk mendatangin orang tua para siswa, karena pada saat pertemuan orang tua dan guru tidak ada satu orang pun yang dating dari kelasmya. Namun sesampainya disana ia mengetahui tiaptiap kegiatan siswa 9F pada saat tidak disekolah, keesokkan hariinya ia menjadikan kegiatan mereka untuk memberitahu siswa 9F bahwasannya mereka masing-masing memiliki bakat yang mereka tidak ketahui.

\section{B. Nilai Pendidikan Karakter Dengan} Sesama Manusia

1. Demokratis
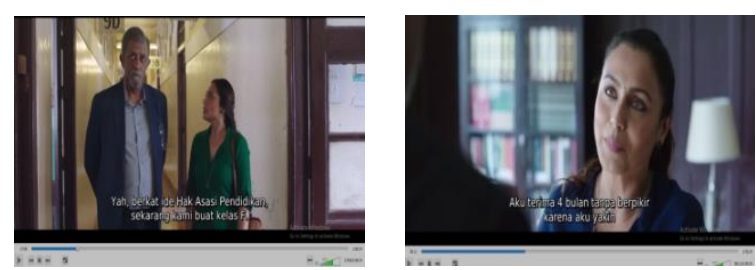

Cara berpikir, bersikap, dan

bertindak,yang menilai sama hak dan kewajiban dirinya dan orang lain. Sikap demokrasi terdapat pada menit ke 00:17:08

Naina : Taka ada kelas sebelumnya? 
Rifani Sayira Wijaya Dan Lisa Septia Dwi Br. Ginting

Nilai Pendidikan Karakter pada Film "Hickhi” (Cegukkan) dan Implementasinya Terhadap Pembelajaran Bahasa Indonesia

Kepala Sekolah : yah, berkat ide Hak Asasi Pendidikan, sekarang kami buat kelas F, yang terisi hanya 14 anak.

Sikap demokrasi terdapat pada menit ke 00:38:11

Naina : aku terima 4 bulan tanpa berpikir, karena aku yakin, kumohon

Kepala Sekolah : baiklah

(kemudian, berjabat tangan)

1. Bersahabat/Komunikatif

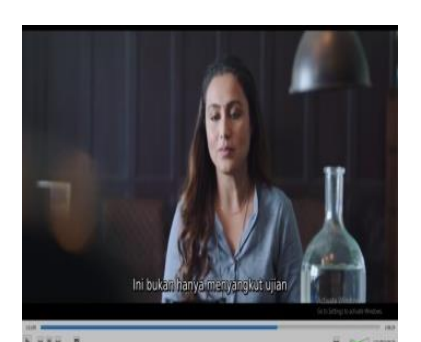

Tindakan yang
memperlihatkan
rasar senang
$\begin{array}{lr}\text { bernicara, } \\ \text { bergaul, dan } \\ \text { bekerja rama } \\ \text { dengan rang }\end{array}$

lain. Sikap bersahabat/komunikatif terdapat pada menit ke 01:21:09

Naina : pak, ini bukan hanya menyangkut ujian saja, ini menyangkut masa depan mereka pak, tolonglah.

2. Menghargai Prestasi

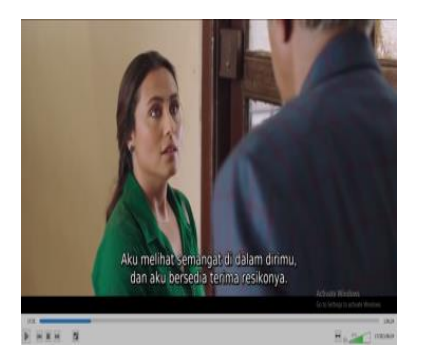

Sikap dan tindakan yang mendorong

dirinya untuk menghasilkan

sesuatu yang berguna bagi masyarakat dan mengakui serta menghormati keberhasilan orang lain . Sikap menghargai prestasi terdapat pada menit ke 00:17:35

Kepala Sekolah : aku melihat semangat tinggi pada dirimu, dan aku bersedia menerima resikonya. Jujur, aku tak mungkin menawarkan pekerjaan ini kepadamu jika dalam keadaan biasa, keadaanya tidak biasa.

\section{B. Nilai Pendidikan Karakter Dengan Kebangsaan}

1. Toleransi

Sikap dan tindakan yang menghargai perbedaan agama, suku,etnis, pendapat, sikap, saran, ataupun tindakan orang lain yang berbeda dari dirinya .

Sikap toleransi terdapat pada menit ke 00:14:55

Perduli akan setiap kekurangan siswa dan menerimanya.

Pak Khan : disekolah ini, tiap orang dating kesini untuk belajar. Dan hari ini itu kau sudah mengajari kami sesuatu. Atas nama St'Notker (nama sekolah), aku berjanji bahwa kami akan memperlkukkanmu seoerti murid lainnya.

Sikap toleransi terdapat pada menit ke 01:21:51

Kepala Sekolah : Bu Mathur, anda adalah guru yang baik, tetapi berurusan dengan kelas yang salah, ini bukan salah anda, ini salah ku. Aku yang memberi

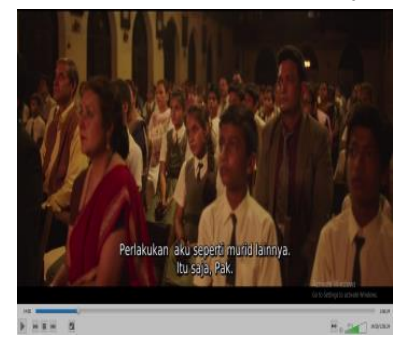

kelas itu.

Aku takut

kami

kehilangan guru yang baik bersama kelas 9F.

Implementasi Film “Hickhi" Pada

Pembelajaran Bahasa Indonesia

Didalam pembelajaran Bahasa

Indonesia bukan saja diterapkannya pembelajaran mengenai membaca dan menulis saja. Implementasi dalam pembelajaran yang sangat relevan adalah pengembangan pemebelajaran nilai karakter peserta didik dan dapat menumbuhkan sifat atau kesadaran siswa agar untuk lebih banyak banyak menonton film yang memiliki nilai-nilai baik untuk meningkatkan seluruh pemahaman dan pengertian tentang sekitar ataupun lingkungan, nilai-nilai pendidikan dapat menemui ide baru, serta mampu membentuk watak dan karakter atapun kepribadian yang jauh lebih baik lagi, kemudian meningkatkan rasa peduli lingkungan, sosial, dan budaya, berkembangnya nilai rasa dan karya. Melalui film "hickhi" peserta didik dapat mempertajam perasan, penalran, dan kepekaan terhadap pentingnya pendidikan, orang yang lebih tua, dan sesamanya. Karena dalam film "hickhi" banyak nilai-nilai yang dijadikan contoh untu menjadi manusia yang lebih baik dan berguna buat orang lain, lingkungan sekitar, dan kehidupan yang akan datang.

\section{SIMPULAN}

Nilai-nilai pendidikan karakter berjumlah 18 yang diantaranya terdapat nilai religius, jujur, tolenrasi, disiplin, kerja keras, kreatif, mandiri, demokratis, rasa ingin tau, semangat kebangsaan, cinta tanah air, menghargai prestasi, bersahabat/komunikatif, cinta damai, gemar membaca, peduli lingkungan, peduli sosial, tanggung jawab, tetapi penulis hanya menganalisis hanya 10 nilai pendidikan karakter saja yang di bagi menjadi 3 bagian 
Rifani Sayira Wijaya Dan Lisa Septia Dwi Br. Ginting

Nilai Pendidikan Karakter pada Film "Hickhi” (Cegukkan) dan Implementasinya Terhadap Pembelajaran Bahasa Indonesia

nilai pendidikan karakter yaitu nilai pendidikan karakter dengan diri sendiri, nilai pendidikan karakter dengan kebangsaan. Maka dari itu implementasinya pada pembelajaran bahasa indonesia yaitu setiap peserta didik harus diajarakan untuk bisa saling menghargai satu sama lain, menghargai keberhasilan orang lain, dan peserta didik harus bisa mudah di terima oleh lingkungan sekitarnya.

\section{SARAN}

Sangat banyak orang beranggapan bahwa film hanya sebagai penghibur semata, oleh karena pemikiran yang seperti tersebut harus di ubah dan di hilangkan agar peserta didik memiliki perkembangan yang jauh lebih meningkat atau lebih baik, film bisa dijadikan sebagai bahan pelajaran.

\section{DAFTAR PUSTAKA}

Fardanmfn.wordpress.com/2018/06/25/Rese nsi Film Hickhi 2018 by Pemuda Kampong Luara' AksaraPustaka-Ralita.

Moeleong, lexy. Metodologi Penelitian Kualitatif. Bandung: Rosdakarya.

Rumah Inspirasi.2019. 18 Jenis Nilai-Nilai Pendidikan Karakter by All Rights Reserved.

Tirto.id. Sinopsis Film Hichki. All rights reserved 2021

Universitas Pendidikan Indonesia repository.upi.edu.perpustakaan. upi.edu 